ARTICLE

\title{
Identification of active catalysts for the acceptorless dehydrogenation of alcohols to carbonyls
}

\author{
Tao Wang (iD ${ }^{1 凶}$, Jin Sha ${ }^{2}$, Maarten Sabbe $\mathbb{B}^{3}{ }^{3}$, Philippe Sautet (iD ${ }^{4,5 凶}$, Marc Pera-Titus ${ }^{2 凶} \&$ \\ Carine Michel (10 ${ }^{6 \times}$
}

Acceptorless dehydrogenation into carbonyls and molecular hydrogen is an attractive strategy to valorize (biobased) alcohols. Using 2-octanol dehydrogenation as benchmark reaction in a continuous reactor, a library of metal-supported catalysts is tested to validate the predictive level of catalytic activity for combined DFT and micro-kinetic modeling. Based on a series of transition metals, scaling relations are determined as a function of two descriptors, i.e. the surface binding energies of atomic carbon and oxygen. Then, a volcanoshape relation based on both descriptors is derived, paving the way to further optimization of active catalysts. Evaluation of 294 diluted alloys but also a series of carbides and nitrides with the volcano map identified 12 promising candidates with potentially improved activity for alcohol dehydrogenation, which provides useful guidance for experimental catalyst design. Further screening identifies $\beta-\mathrm{Mo}_{2} \mathrm{~N}$ and $\gamma-\mathrm{Mo}_{2} \mathrm{~N}$ exposing mostly (001) and (100) facets as potential candidates for alcohol dehydrogenation.

\footnotetext{
${ }^{1}$ Center of Artificial Photosynthesis for Solar Fuels, School of Science, Westlake University, Hangzhou, Zhejiang Province, China. ${ }^{2}$ Eco-Efficient Products and Processes Laboratory (E2P2L), UMI 3464 CNRS - Solvay, Shanghai, China. ${ }^{3}$ Department of Materials, Textiles and Chemical Engineering, Ghent University, Zwijnaarde, Belgium. ${ }^{4}$ Department of Chemical and Biomolecular Engineering, University of California, Los Angeles, Los Angeles, CA, USA. ${ }^{5}$ Department of Chemistry and Biochemistry, University of California, Los Angeles, Los Angeles, CA, USA. ${ }^{6}$ Univ Lyon, ENS de Lyon, CNRS UMR 5182, Laboratoire de Chimie,

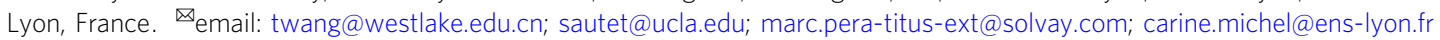


T he oxidation of alcohols to carbonyl compounds is one of the most fundamental and useful organic reactions for both academic research and industrial applications ${ }^{1}$. Traditionally, the aerobic oxidation of alcohols relying on green oxidants such as molecular oxygen and hydrogen peroxide instead of inorganic oxidants has been regarded as economically and environmentally promising ${ }^{2}$. Heterogeneous catalysts based on transition metals such as $\mathrm{Pd}^{3}, \mathrm{Pt}^{4}, \mathrm{Au}^{5-7}$, and $\mathrm{Ru}^{8}$ are often regarded as active and efficient for oxidation reactions. An alternative approach is to eliminate the hydrogen acceptor and produce not only a highly valuable carbonyl compound, but also $\mathrm{H}_{2}{ }^{9}$. Although acceptorless dehydrogenation reactions are less thermodynamically favored than oxidation reactions ${ }^{10}$, they limit the risk of over-oxidation to the carboxylic acid ${ }^{11}$. Besides, these reactions are significant for $\mathrm{H}_{2}$ production from biomass-based alcohols $^{12}$, as well as for H-transfer reactions ${ }^{13,14}$.

In homogenous catalysis, successful catalysts for acceptorless alcohol dehydrogenation into carbonyl compounds rely on $\mathrm{Ru}^{11,15}$ $\operatorname{Ir}^{16-18}$ and $\mathrm{Os}^{19}$ complexes. Comprehensive reviews on the important progress of homogenously based acceptorless alcohol dehydrogenation reactions are also available ${ }^{20,21}$. However, such systems suffer from the common drawbacks associated to homogenous catalysis, namely complex recycling, as well as the use of additives, which hinder large-scale industrial applications. To avoid these shortcomings, heterogeneous catalysis has received high priority and a series of transition metals were tested for this reaction, for which $\mathrm{Ru}^{22}, \mathrm{Pt}^{23}, \mathrm{Pd}^{24}, \mathrm{Re}^{25}, \mathrm{Ag}^{26,27}, \mathrm{Au}^{28}, \mathrm{Fe}^{29}$, $\mathrm{Mn}^{29}, \mathrm{Cu}^{30}, \mathrm{Co}^{29,31,32}$ and $\mathrm{Ni}^{33,34}$, and alloys were identified as potential active catalysts, as recently reviewed by Shimizu et al. ${ }^{35}$.

To assist the experimental development and smart catalyst design, theoretical calculations can play a complementary and even decisive role $^{36,37}$. In the last decade, DFT-based mechanistic investigations for alcohol dehydrogenation reactions have become easily available. For example, methanol and ethanol adsorption and dehydrogenation into $\mathrm{CO}$ and $\mathrm{H}_{2}$ have been widely studied on the surface of different transition metals such as $\mathrm{Pt}^{38,39}, \mathrm{Pd}^{40}, \mathrm{Ir}^{41}$, $\mathrm{Rh}^{42}, \mathrm{Ni}^{43}$ and $\mathrm{Cu}^{44}$ using both periodic slab models and metal clusters. These calculations provide useful energetic information on the alcohol decomposition pathways on each individual metal. Furthermore, Brønsted-Evans-Polanyi (BEP) correlations based on DFT studies focusing on $\mathrm{C}-\mathrm{H}$ and $\mathrm{O}-\mathrm{H}$ bond cleavage in alcohols have been reported for predicting activity trends for methanol ${ }^{45}$, ethanol $^{46}$, and polyalcohol dehydrogenation ${ }^{47}$. In particular, Lausche et al. ${ }^{48}$. reported the dehydrogenation of $\mathrm{CH}_{3} \mathrm{OH}$ on the (211) surface of $\mathrm{Cu}, \mathrm{Ag}, \mathrm{Pt}, \mathrm{Pd}$ and Rh catalysts, and formulated a descriptor-based kinetic modeling approach for predicting the catalytic activity of a library of heterogeneous catalysts.

Owing to the industrial relevance of aliphatic alcohol dehydrogenation into aldehydes and ketones, it is of great significance to find and even design efficient catalysts for this reaction. Despite the extensive experimental and theoretical investigations reported to date on transition metals, including a first-principle predictive micro-kinetic study ${ }^{49}$, no combined experiment-theory report is available for fast, cost-effective, and time-efficient in silico screening of metals for alcohol dehydrogenation. Herein, we present a DFTbased micro-kinetic study to predict the activity of transition metals for alcohol dehydrogenation into ketones. Our strategy focuses on building an experimentally verified activity-descriptor relation to efficiently screen different types of catalysts and provide guidance for experimental design and discovery of promising catalysts for acceptorless alcohol dehydrogenation into ketones and $\mathrm{H}_{2}$.

\section{Results and discussion}

DFT calculations for the model reaction: DFT calculations were conducted to explore the alcohol dehydrogenation mechanism on a group of transition metal catalysts. Methanol $\left(\mathrm{CH}_{3} \mathrm{OH}\right)$ dehydrogenation into formaldehyde $\left(\mathrm{CH}_{2} \mathrm{O}\right)$ and $\mathrm{H}_{2}$ was first chosen as model reaction to avoid the intrinsic difficulties ascribed to configuration space exploration. Two pathways are a priori possible for alcohol dehydrogenation: (1) the alkoxy path $\mathrm{CH}_{3} \mathrm{OH} \rightarrow$ $\mathrm{CH}_{3} \mathrm{O}+\mathrm{H} \rightarrow \mathrm{CH}_{2} \mathrm{O}+2 \mathrm{H}$; and (2) the hydroxyalkyl path $\mathrm{CH}_{3} \mathrm{OH} \rightarrow \mathrm{CH}_{2} \mathrm{OH}+\mathrm{H} \rightarrow \mathrm{CH}_{2} \mathrm{O}+2 \mathrm{H}$.

As an illustrative example, Fig. 1a,b represent the free energy profiles at $453 \mathrm{~K}$ and the initial (IS), final (FS), and transition state (TS) structures on $\mathrm{Pt}(111)$ surface. $\mathrm{CH}_{3} \mathrm{OH}$ adsorbs on the top site with its $\mathrm{O}$ atom interacting with one surface $\mathrm{Pt}$ atom. For the alkoxy path, the $\mathrm{O}-\mathrm{H}$ bond breaking in $\mathrm{CH}_{3} \mathrm{OH}$ to form the alkoxy $\mathrm{CH}_{3} \mathrm{O}$ intermediate has an energy barrier of $0.78 \mathrm{eV}$ and an $\mathrm{O}-\mathrm{H}$ bond length of $1.64 \AA$, and this step is endothermic by $0.46 \mathrm{eV}$. Further $\mathrm{C}-\mathrm{H}$ bond cleavage breaking in $\mathrm{CH}_{3} \mathrm{O}$ to form $\mathrm{CH}_{2} \mathrm{O}$ has an energy barrier of only $0.16 \mathrm{eV}$ and a $\mathrm{C}-\mathrm{H}$ bond length of $1.60 \AA$, and this is exothermic by $0.50 \mathrm{eV}$. For the hydroxyalkyl path, the $\mathrm{C}-\mathrm{H}$ bond breaking in $\mathrm{CH}_{3} \mathrm{OH}$ yields the $\mathrm{CH}_{2} \mathrm{OH}$ intermediate with a $\mathrm{C}-\mathrm{H}$ bond length of $1.50 \AA$ in the transition state. This step has an energy barrier of $0.53 \mathrm{eV}$ and is exothermic by $0.35 \mathrm{eV}$. Further $\mathrm{O}-\mathrm{H}$ bond breaking in $\mathrm{CH}_{2} \mathrm{OH}$ to form $\mathrm{CH}_{2} \mathrm{O}$ has an energy barrier of $0.76 \mathrm{eV}$ with an $\mathrm{O}-\mathrm{H}$ bond length of $1.58 \AA$ in TS, and is endothermic by $0.31 \mathrm{eV}$. According to the free energy profiles, the most favorable path on $\mathrm{Pt}(111)$ is the hydroxyalkyl one with more stable intermediates and lower energy barriers. Adsorbate-adsorbate interactions, which can be affected by the $\mathrm{H}$ coverage (see potential energy diagrams in Supplementary Fig. 1), were assumed to be comparable for the different catalysts. The changes on adsorption and activation energies were calculated to be limited to $0.1 \mathrm{eV}$ for the dominant hydroxyalkyl pathway (based on the degree of rate control analysis in Supplementary Tables 1 and 2), except for $\mathrm{CH}_{2} \mathrm{O}^{*}(0.35$ $\mathrm{eV})$ on $\mathrm{Pt}(111)$ surface. As a consequence, coverage effects can impact the TOF by orders of magnitudes, but we expect the catalyst ranking to be conserved.

Analogous calculations were performed on $\mathrm{Co}(111), \mathrm{Rh}(111)$, $\operatorname{Ir}(111), \operatorname{Ni}(111), \operatorname{Pd}(111), \operatorname{Os}(0001), \operatorname{Ru}(0001)$, and $\operatorname{Re}(0001)$ surfaces and the corresponding energetic and structural information are given in the supplementary Tables 3-5 and Figs. 2-11. Clearly, these metals can provide different favorable reaction paths. For example, on Pd and Ir, the hydroxyalkyl path should be the most favorable with a stable hydroxyalkyl intermediate. On the more oxophilic $\mathrm{Ni}, \mathrm{Co}$, and $\mathrm{Ru}$ surfaces, the alkoxy intermediate is strongly stabilized and becomes even more stable than $\mathrm{CH}_{2} \mathrm{O}$, so that the alkoxy path should be the most favorable one. However, the alkoxy intermediate might also be too stable and prevent its complete dehydrogenation. In this view, a detailed micro-kinetic modeling will provide more insights into the impact of the relative stability of the intermediates and transition states on the favorable reaction pathways as shown in the following section.

General activity trends of transition metals in $\mathrm{CH}_{3} \mathrm{OH}$ dehydrogenation: To enable catalyst optimization and build an easily accessible descriptor for activity prediction, the CatMAP software was used to simulate maps of turnover frequency (TOF) as a function of catalyst descriptors ${ }^{50}$. Here, we used the adsorption energy of atomic $\mathrm{C}$ and $\mathrm{O}$ as natural and quick-to-evaluate descriptors of the overall reaction kinetics. In this method, scaling ${ }^{51}$ and $\mathrm{BEP}^{52}$ relations were applied to acquire the energetic information of the whole reaction network, which provides a basis for further micro-kinetic modeling. Based on systematic DFT simulations of $\mathrm{CH}_{3} \mathrm{OH}$ dehydrogenation mechanism on nine transition metals, we tested the quality of linear relationships. A MAE $<0.2 \mathrm{eV}$ for all the scaling and BEP relations for this reaction provides good basis for further micro-kinetic modeling (Supplementary Table 6). To place the reaction system far 

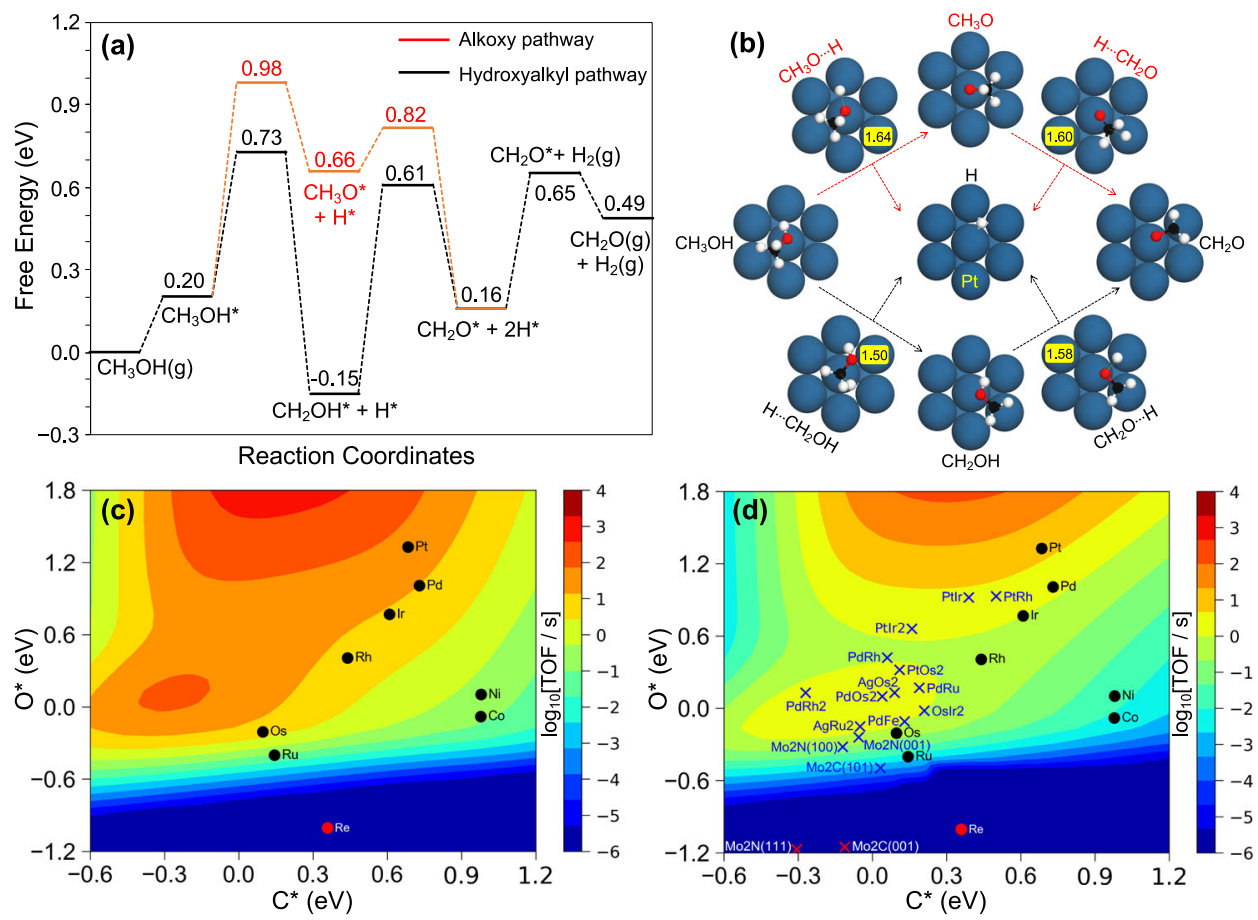

Fig. 1 DFT calculations exploring methanol dehydrogenation into formaldehyde. Free energy profile a and structures of related intermediates and transition states $\mathbf{b}$ for $\mathrm{CH}_{3} \mathrm{OH}$ dehydrogenation on $\mathrm{Pt}(111)$ via the hydroxyalkyl path (in black) and the alkoxy path (in red) using molecular $\mathrm{CH}_{3} \mathrm{OH}$ and the pristine surface as energy reference at $453 \mathrm{~K}$; c Turnover frequencies (TOFs) of $\mathrm{CH}_{2} \mathrm{O}$ production from $\mathrm{CH}_{3} \mathrm{OH}$ as a function of the $\mathrm{C}$ and $\mathrm{O}$ adsorption energies (referred to $\mathrm{CH}_{3} \mathrm{OH}, \mathrm{H}_{2} \mathrm{O}$ and $\mathrm{H}_{2}$ ) at $453 \mathrm{~K}$ with $\mathrm{p}_{\mathrm{CH}} \mathrm{OH}=101 \mathrm{kPa}(0.1 \%$ conversion), and $\mathbf{d}$ turnover frequencies (TOFs) of 2-octanone production from 2-octanol at $p_{\mathrm{OL}}=101 \mathrm{kPa}$ (15\% conversion). ( $\mathrm{C}$ in black, $\mathrm{O}$ in red, $\mathrm{H}$ in white, $\mathrm{Pt}$ in blue, numbers in the yellow box provide the length $(\AA)$ of bond being broken in TS).

from equilibrium $\left(0.19 \%\right.$ for $\left.\mathrm{CH}_{3} \mathrm{OH}\right)$, a $0.1 \%$ conversion at 453 $\mathrm{K}$ and $101 \mathrm{kPa} \mathrm{CH} \mathrm{CH}_{3} \mathrm{OH}$ was chosen as input reaction condition for kinetic modeling with CatMAP, which corresponds to $p_{\mathrm{CH} 3 \mathrm{OH}}=99.9 \mathrm{kPa}$ and $p_{\mathrm{CH} 2 \mathrm{O}}=p_{\mathrm{H} 2}=0.1 \mathrm{kPa}$. Turnover frequencies were used to describe the activity of each catalyst. As shown in Fig. 1c, two high activity zones are observed in the volcano plot, which represent the hydroxyalkyl (above, low $\Delta \mathrm{E}_{\mathrm{O}}$ ) and alkoxy (below, strong $\Delta \mathrm{E}_{\mathrm{O}}$ ) reaction pathways, respectively. A clear activity order for the different metals can be discerned.

Validation of theoretically predicted activity trend by experimental 2-octanol dehydrogenation: Evaluating directly the agreement between micro-kinetic modeling and experimental results will provide validation of the theoretically identified activity trends of metals for $\mathrm{CH}_{3} \mathrm{OH}$ dehydrogenation shown in Fig. 1c, which is essential for rational catalyst screening. For better comparison with the experimental results, we modeled 2-octanol dehydrogenation on the metal catalysts by correcting the $\mathrm{CH}_{3} \mathrm{OH} / \mathrm{CH}_{2} \mathrm{O}$-to-2-octanol/2-octanone reaction free energies. For example, the overall gas-phase equilibrium constant from $\mathrm{CH}_{3} \mathrm{OH}$ to $\mathrm{CH}_{2} \mathrm{O}$ and $\mathrm{H}_{2}$ amounts $8.40 \times 10^{-5}$ bar at $453 \mathrm{~K}$ and $101 \mathrm{kPa}$ using default NASA thermochemical polynomials ${ }^{53}$. At this temperature, the equilibrium constant for 2-octanol derived from the same thermochemical database is much higher $(7.26 \times$ $10^{-1}$ bar) due to the difference between the enthalpies of formation of $\mathrm{CH}_{2} \mathrm{O} / 2$-octanone and $\mathrm{CH}_{3} \mathrm{OH} / 2$-octanol. As a result, the $\mathrm{CH}_{3} \mathrm{OH}$ dehydrogenation equilibrium conversion amounts only $0.19 \%$ at $101 \mathrm{kPa}$, while it becomes $56.3 \%$ for 2 -octanol dehydrogenation at $101 \mathrm{kPa}$. In this view, the micro-kinetic simulations for 2-octanol dehydrogenation were computed from the DFT data for $\mathrm{CH}_{3} \mathrm{OH}$ dehydrogenation by multiplying the alcohol adsorption and ketone desorption equilibrium constants by the factor $\left(7.26 \times 10^{-1} / 8.40 \times 10^{-5}\right)^{0.5}$. With this correction, we built a map for 2-octanol dehydrogenation to 2 -octanone at
$453 \mathrm{~K}$ and $101 \mathrm{kPa}$ as a function of $\mathrm{C}$ and $\mathrm{O}$ adsorption energies (Fig. 1d). Clearly, the trend for the different metals is similar to that of $\mathrm{CH}_{3} \mathrm{OH}$ (Fig. 1c) and 2-octanol (Fig. 1d) dehydrogenation, which is a good basis for further catalyst screening.

With this established activity volcano map for 2-octanol dehydrogenation, our first effort was to experimentally validate the predicted activity trend for different transition metals in Fig. 1d. To this aim, a series of transition metal catalysts was synthesized based on alumina-supported $\mathrm{Ni}, \mathrm{Co}, \mathrm{Ru}, \mathrm{Pd}$, and $\mathrm{Pt}$ catalysts, and silica-supported Pd and Pt (see SI for details). The main properties of the catalysts are listed in Supplementary Table 7, whereas the metal reducibility, dispersion and particle size distributions are compiled in Supplementary Figs. 12 and 13. The catalytic activity was measured in a continuous fixed-bed reactor at $453 \mathrm{~K}$ using a catalyst weight in the range of $33-430 \mathrm{mg}$ and a 2-octanol flowrate in the range $1.2-2.4 \mathrm{~mL} / \mathrm{min}$. The reaction conditions were adjusted to achieve low conversion $(<50 \%)$, far from chemical equilibrium. At the tested conditions, $\mathrm{Pt}$ exhibited the highest dehydrogenation activity per surface metal atom towards 2-octanone $\left(1.19 \times 10^{-1} \mathrm{~s}^{-1}\right.$ for aluminasupported and $1.09 \times 10^{-1} \mathrm{~s}^{-1}$ for silica supported), followed by Pd $\left(2.38 \times 10^{-2} \mathrm{~s}^{-1}\right.$ for alumina-supported and $2.42 \times 10^{-3} \mathrm{~s}^{-1}$ for silica-supported), $\mathrm{Ni}\left(2.26 \times 10^{-2} \mathrm{~s}^{-1}\right)$, Co $\left(1.62 \times 10^{-2} \mathrm{~s}^{-1}\right)$ and $\mathrm{Ru}\left(0.87 \times 10^{-2} \mathrm{~s}^{-1}\right)$ (Fig. 2a, Supplementary Table 8$)$. This trend agrees well with the prediction in Fig. 1d as illustrated in the parity plot of experimental TOF vs. predicted TOF for 2-octanol dehydrogenation (Fig. 2b). In all cases, 1-octene was observed as byproduct with a selectivity $<5 \%$ for $\mathrm{Co}, \mathrm{Pd}$ and $\mathrm{Pt}$, and $<15 \%$ for $\mathrm{Ni}$ and $\mathrm{Ru}$ (Supplementary Fig. 14). The quantitative agreement is remarkable for $\mathrm{Ru}, \mathrm{Co}$ and $\mathrm{Ni}$. One can note that the measured TOF for Pt and Pd are significantly lower than the calculated ones (by a factor of 100 and 30 respectively). This may be due to coking, that would decrease the number of 

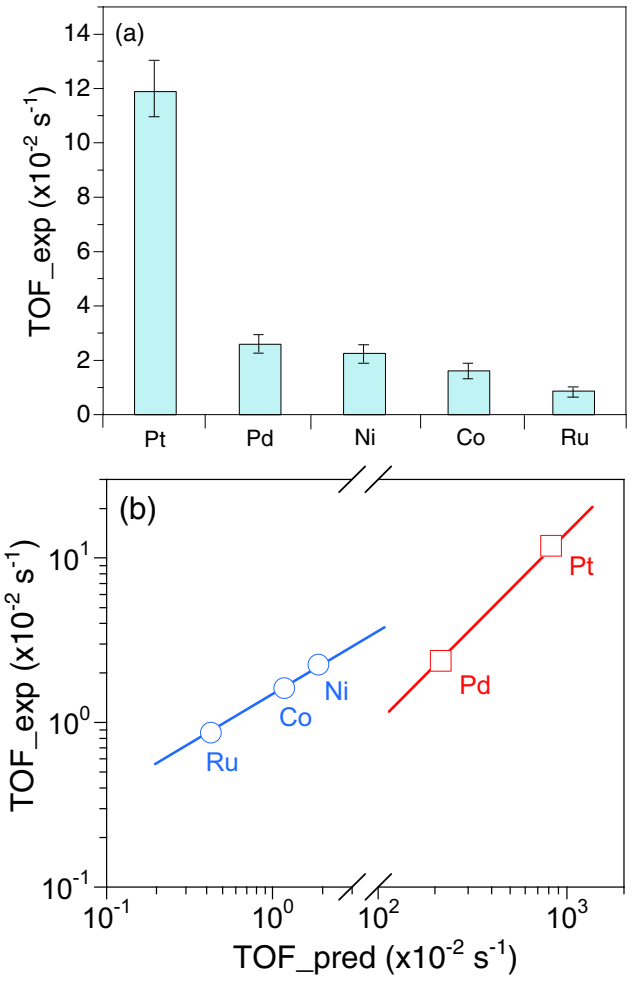

Fig. 2 2-octanol dehydrogenation over alumina-supported metal catalysts. a Experimental TOF and $\mathbf{b}$ predicted TOF vs. experimental TOF. Reaction conditions: $\mathrm{T}=453 \mathrm{~K}, \mathrm{P}=101 \mathrm{kPa}, \mathrm{p}_{\mathrm{OL}}=14-20 \mathrm{kPa}, \mathrm{p}_{\mathrm{H} 2}=44$ $\mathrm{kPa}, \mathrm{WHSV}_{\mathrm{OL}}=3.3-32 \mathrm{~h}^{-1}$. The catalysts were pre-reduced for $4 \mathrm{~h}$ at different temperatures according to the $\mathrm{H}_{2}$-TPR profiles (Supplementary Fig. 16): $453 \mathrm{~K}$ for $\mathrm{Pd} / \mathrm{Al}_{2} \mathrm{O}_{3}, 473 \mathrm{~K}$ for $\mathrm{Pt} / \mathrm{Al}_{2} \mathrm{O}_{3}$ and $\mathrm{Ru} / \mathrm{Al}_{2} \mathrm{O}_{3}, 723 \mathrm{~K}$ for $\mathrm{Co} / \mathrm{Al}_{2} \mathrm{O}_{3}, 773 \mathrm{~K}$ for $\mathrm{Ni} / \mathrm{Al}_{2} \mathrm{O}_{3}$. The error bars in (a) refer to confidence intervals including error propagation.

accessible sites and accordingly the catalytic activity (Supplementary Fig. 15, Supplementary Table 8 ). The effect of coking is also apparent on the other metals with a coke loading always larger than $7 \mathrm{~mol} \mathrm{C} / \mathrm{mol}$ surface metal. Since the catalysts are active despite coke loading being well above a few monolayers, the amount of coke cannot be quantitatively related to a loss of active sites. Co-adsorbed $\mathrm{H}$ is also limiting the predicted TOF: on the very active $\mathrm{Pt}$, we found this effect to yield to a drop of the predicted TOF down to $3.1 \times 10^{-2} \mathrm{~s}^{-1}$ which matches the experimental TOF (see also Fig. 3b below). Overall, the jointed theoretical and experimental effort provides a good basis for extensive catalyst screening.

Predicted new catalysts: On the basis of the experimentally validated TOF map in Fig. 1d, we are able to perform an efficient screening of potential active catalysts for alcohol dehydrogenation. Following a similar strategy as in our recent work on alcohol amination $^{54}$, we computed the $\mathrm{C}$ and $\mathrm{O}$ adsorption energies for 294 dilute alloys and evaluated their credentials for dehydrogenation (Supplementary Table 9). As shown in Supplementary Fig. 17, dilute alloys of $B$ in $A$ (noted $A$ ) were modeled by substituting one $(\mathrm{n}=1)$ or two neighboring $(\mathrm{n}=2)$ A atoms on a $p(3 \times 3)$ supercell by metal $\mathrm{B}$, resulting in a B coverage of 0.11 or $0.22 \mathrm{ML}$ respectively. This corresponds to single atom alloys as described in the literature ${ }^{55}$, or dimer-atom alloys. This procedure eventually identifies 12 out of those 294 alloys with potentially high activity in alcohol dehydrogenation as shown in the blue crosses in Fig. 1d, spanning the region of the secondary maximum in reaction rate located around $\mathrm{E}_{\mathrm{O}}=\mathrm{E}_{\mathrm{C}}=0$, since the global maximum on the map (top-left volcano peaks in Fig. 1d)
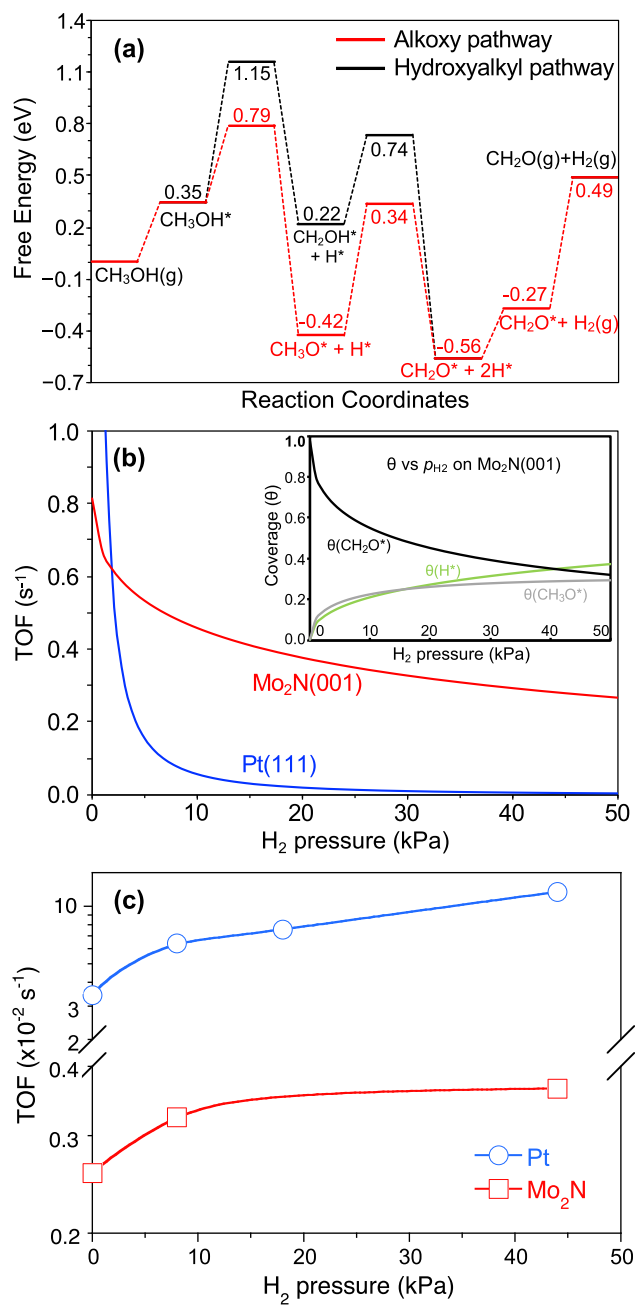

Fig. 3 Alcohol dehydrogenation over $\mathbf{M o}_{\mathbf{2}} \mathbf{N}$. a Free energy diagram for $\mathrm{CH}_{3} \mathrm{OH}$ dehydrogenation at $453 \mathrm{~K}$ on $\beta-\mathrm{Mo}_{2} \mathrm{~N}(001)$ surface; $\boldsymbol{b}$ Predicted TOF of $\mathrm{CH}_{2} \mathrm{O}$ from $\mathrm{CH}_{3} \mathrm{OH}$ dehydrogenation on $\mathrm{Pt}(111)$ and $\beta-\mathrm{Mo}_{2} \mathrm{~N}(001)$ surfaces at variable cofeeding $\mathrm{H}_{2}$ partial pressure $\left(p_{\mathrm{H} 2}\right)$ at $453 \mathrm{~K}$ with $p_{\mathrm{CH} 3 \mathrm{OH}}=14 \mathrm{kPa}$ as well as the coverage changes of important intermediates on $\beta-\mathrm{Mo}_{2} \mathrm{~N}$ (001) surface with $p_{\mathrm{H} 2}$; c experimental evolution of the TOF for 2-octanol dehydrogenation as a function of the $\mathrm{H}_{2}$ partial pressure for $\mathrm{Pt}$ and $\mathrm{Mo}_{2} \mathrm{~N}$.

lies out of the energy span covered by the considered transition metals and alloys. To our knowledge, there is no clear synthesis protocol to control those specific alloys (e.g., $\mathrm{AgRu}_{2}$ ). We believe that further state-of-the-art experimental synthesis and tests of these candidates would provide essential contributions for catalyst development targeting alcohol acceptorless dehydrogenation. Besides, the predicted candidates are mainly based on noble metals ( $\mathrm{Pt}, \mathrm{Pd}, \mathrm{Rh}, \mathrm{Ru}$, etc.), which potentially hinders large-scale applications. If non-precious metals are targeted, a new type of active site is needed to potentially reach that region. Therefore, as first trial we focused on a series of metal carbide and nitride catalysts owing to their noble-metal-like activity in hydrotreating reactions ${ }^{56}$, for which close-packed model surfaces were selected. We verified that carbide and nitride catalysts follow the same scaling relations as the metal catalysts in Supplementary Fig. 18. As shown in Fig. 1d and Supplementary Table 8, the close packed surfaces of carbide and nitride catalysts such as hexagonal $\mathrm{Mo}_{2} \mathrm{C}$ (001), cubic $\gamma-\mathrm{Mo}_{2} \mathrm{~N}(111)$ and tetragonal $\beta-\mathrm{Mo}_{2} \mathrm{~N}(112)$ surfaces fall into the dark blue region on the bottom of the map due to their strong $\mathrm{O}$ adsorption, reflecting their potentially low activity 
for alcohol dehydrogenation. However, close packed surfaces are not often the most representative facets of carbide and nitride particles, and hence do not reflect entirely their catalytic properties. As a result, based on surface stability and Wulff construction information, the other exposed hexagonal $\mathrm{Mo}_{2} \mathrm{C}(101)^{57}$, $\gamma-\mathrm{Mo}_{2} \mathrm{~N}(100)$ and $\beta-\mathrm{Mo}_{2} \mathrm{~N}(001)$ surfaces were also chosen for computing the $\mathrm{C}$ and $\mathrm{O}$ adsorption energies. Overall, both $\mathrm{C}$ and $\mathrm{O}$ adsorption energies shift close to the active region, where $\beta$ $\mathrm{Mo}_{2} \mathrm{~N}(001)$ and $\gamma-\mathrm{Mo}_{2} \mathrm{~N}(100)$ with very similar surface structures (see the optimized coordinates in the Supplementary Data 1) are close to the secondary maximum of the volcano (Fig. 1d).

To further validate this prediction, the detailed $\mathrm{CH}_{3} \mathrm{OH}$ dehydrogenation mechanism on $\beta-\mathrm{Mo}_{2} \mathrm{~N}(001)$ surface was computed, and the free energy diagram is shown in Fig. 3a. Then, a micro-kinetic model was established to compare the performance of $\beta-\mathrm{Mo}_{2} \mathrm{~N}(001)$ surface with the $\mathrm{Pt}(111)$ surface in Fig. 3b. In the kinetic modeling, the role of $\mathrm{H}_{2}$ co-feeding at $453 \mathrm{~K}$ and $p_{\mathrm{CH} 3 \mathrm{OH}}=14 \mathrm{kPa}$ was first considered to mimic the experimental conditions. Figure $3 \mathrm{~b}$ reveals that the TOF of both $\mathrm{Pt}$ and $\mathrm{Mo}_{2} \mathrm{~N}$ catalysts decreases at higher $p_{\mathrm{H} 2}$ in the feed, and $\mathrm{Pt}(111)$ shows much sharper decline. As soon as $\mathrm{H}_{2}$ is co-fed with the alcohol, $\beta-\mathrm{Mo}_{2} \mathrm{~N}(001)$ is expected to exhibit a higher TOF than $\mathrm{Pt}$ (111): the $\beta-\mathrm{Mo}_{2} \mathrm{~N}(001)$ surface is potentially active for alcohol dehydrogenation.

With such predictions in hand, we prepared in situ a $\mathrm{Mo}_{2} \mathrm{~N}$ sample using a reported method (see Supplementary Methods for details). The sample was highly pure and crystalline based on the $\beta-\mathrm{Mo}_{2} \mathrm{~N}$ phase, with traces of metal Mo, as inferred from XRD (Supplementary Fig. 19) and HRTEM (Supplementary Fig. 20). The average particle size was $43 \mathrm{~nm}$, whereas the Mo dispersion was $c a .2 .5 \%$ by assuming a spherical particle shape. The catalytic activity was measured in a continuous fixed-bed reactor using $200 \mathrm{mg} \mathrm{Mo} 2 \mathrm{~N}$ and a 2-octanol flowrate of $1.2 \mathrm{~mL} / \mathrm{min}$ and $p_{\mathrm{H} 2}=$ $5.5 \mathrm{kPa}$. The 2 -octanol conversion was $7 \%$ with $100 \%$ selectivity of 2-octanone. At these conditions, the dehydrogenation activity per total surface Mo was $2.85 \times 10^{-3} \mathrm{~s}^{-1}$. This value is $\sim 30$ times lower than the calculated TOF in Fig. 1d. This can be explained by the limited ratio of (001) facets in our synthesized $\mathrm{Mo}_{2} \mathrm{~N}$ as shown in Supplementary Fig. 20, and by contamination due to strongly bound reaction products and intermediates.

We measured the TOF for $\mathrm{Pt}$ and $\mathrm{Mo}_{2} \mathrm{~N}$ at variable $p_{\mathrm{H} 2}$ in the feed, and the experimental trends are provided in Fig. 3c. A low $p_{\mathrm{H} 2}$ is clearly detrimental to the activity for $\mathrm{Pt}$, while the activity of $\mathrm{Mo}_{2} \mathrm{~N}$ is preserved. This apparent contradiction with the computed results suggests a drop of the number of available sites on Pt when $p_{\mathrm{H} 2}$ is too low. Indeed, a high enough $p_{\mathrm{H} 2}$ is necessary to maintain active sites free of coke, while the calculations assumed a constant number of Pt active sites. This is apparently less detrimental on $\mathrm{Mo}_{2} \mathrm{~N}$, a noticeable advantage of this catalyst. We believe that further state-of-the-art methodology will be able to synthesize phase-pure tetragonal $\beta-\mathrm{Mo}_{2} \mathrm{~N}$ and cubic $\gamma-\mathrm{Mo}_{2} \mathrm{~N}$ exposing mostly (001) and (100) facets, respectively, which could have higher activity in alcohol dehydrogenation.

In conclusion, to identify active catalysts for the conversion of alcohols into aldehydes or ketones and molecular hydrogen, a combined DFT and micro-kinetics approach was validated against experimental data obtained on a benchmark reaction. The reaction pathways of methanol dehydrogenation to formaldehyde and $\mathrm{H}_{2}$ on the close-packed surface of series transition metals (Co, Rh, Ir, Ni, Pd, Pt, Os, Ru, and Re) are systematically calculated and the TOF map as a function of C and $\mathrm{O}$ atoms adsorption energies is proposed with descriptorbased micro-kinetics modeling. The predicted activity trend for different metals is experimentally validated, paving the way to an $a b$ initio screening of active catalysts for alcohol dehydrogenation. The two active plateaux on the volcano map with higher activity are off the range of energies spanned by the close packed transition metals under investigation. Thus, more active catalysts could be found, but not combining such metals into alloys. Evaluation of 294 dilute alloys by combining different elements in periodic table only identified 12 potentially promising candidates with comparable activity compared to the most active Pt catalyst, which will trigger further state-of-art experimental efforts to test their performance. The screening of a series of metal carbides and nitrides revealed that tetragonal $\beta-\mathrm{Mo}_{2} \mathrm{~N}$ and cubic $\gamma-\mathrm{Mo}_{2} \mathrm{~N}$ exposing mostly (001) and (100) facets are potential economically viable candidates to substitute noble metals. We believe the established framework in this work lays a good basis for the discovery of novel catalyst for efficient alcohol dehydrogenation.

\section{Methods}

Materials and methods regarding the experiments can be found in supplementary methods. All computations were performed by applying the plane-wave based density functional theory (DFT) method with the Vienna $A b$ Initio Simulation Package (VASP) and periodic slab models ${ }^{58}$. The electron-ion interaction was described with the projector augmented wave (PAW) method $^{59}$, while the electron exchange and correlation energy was solved within the generalized gradient approximation with the Perdew-Burke-Ernzerhof formalism (GGA-PBE) ${ }^{60}$. An energy cut-off of $400 \mathrm{eV}$ and a second-order Methfessel-Paxton electron smearing with $\sigma=0.2 \mathrm{eV}$ were used to ensure accurate energies with errors less than $1 \mathrm{meV}$ per atom ${ }^{61}$. Geometry optimization was done when forces became smaller than $0.02 \mathrm{eV} / \mathrm{A}$ and the energy difference was lower than $10^{-6} \mathrm{eV}$. A vacuum layer of 12 $\AA$ A between periodically repeated slabs was set to avoid interactions among slabs. The density-dependent $\mathrm{dDsC}$ method was used for the dispersion correction ${ }^{62}$. Nine transition metals were chosen as the model catalysts and the close-packed surfaces of each metal were used to simulate the catalytic activity, i.e., the (111)-p $(3 \times 3)-4 \mathrm{~L}$ surface model of Co, Rh, Ir, Ni, Pd, Pt as well as $(0001)-\mathrm{p}(3 \times 3)-4 \mathrm{~L}$ surface of $\mathrm{Ru}$, Os and Re. Spin-polarization was included for $\mathrm{Ni}$ and Co systems to correctly describe magnetic properties. A $(5 \times 5) \mathrm{k}$-point mesh is used for sampling the Brillouin zone. The nudged elastic band (NEB) method was applied to locate the transition states and stretching frequencies were analyzed to characterize a transition state with only one imaginary frequency ${ }^{63}$.

\section{Data availability}

The coordinates of all optimized structures generated in this study are provided as Supplementary Data 1 .

\section{Code availability}

The code used to perform this work is available at https://github.com/SUNCAT-Center/ catmap under the https://doi.org/10.5281/zenodo.5062182.

Received: 1 February 2021; Accepted: 20 July 2021; Published online: 24 August 2021

\section{References}

1. Mallat, T. \& Baiker, A. Oxidation of alcohols with molecular oxygen on solid catalysts. Chem. Rev. 104, 3037-3058 (2004)

2. Matsumoto, T., Ueno, M., Wang, N. \& Kobayashi, S. Recent advances in immobilized metal catalysts for environmentally benign oxidation of alcohols. Chem. Asian J. 3, 196-214 (2008).

3. Mori, K. et al. Controlled synthesis of hydroxyapatite-supported palladium complexes as highly efficient heterogeneous catalysts. J. Am. Chem. Soc. 124, 11572 (2002).

4. Yamada, Y. M. A., Arakawa, T., Hocke, H. \& Uozumi, Y. A nanoplatinum catalyst for aerobic oxidation of alcohols in water. Angew. Chem. Int. Ed. 46, 704-706 (2007).

5. Hashmi, A. S. K. \& Hutchings, G. J. Nanocrystalline gold catalysis. Angew. Chem. Int. Ed. 45, 7896-7936 (2006).

6. Hutchings, G. J. Nanocrystalline gold and gold palladium alloy catalysts for chemical synthesis. Chem. Commun. 1148-1164 (2008).

7. Della Pina, C., Falletta, E. \& Rossi, M. Update on Selective Oxidation Using Gold. Chem. Soc. Rev. 41, 350-369 (2012).

8. Yamaguchi, K., Mori, K., Mizugaki, T., Ebitani, K. \& Kaneda, K. Creation of a monomeric $\mathrm{Ru}$ species on the surface of hydroxyapatite as an efficient heterogeneous catalyst for aerobic alcohol oxidation. J. Am. Chem. Soc. 122, 7144 (2000) 
9. Friedrich, A. \& Schneider, S. Acceptorless dehydrogenation of alcohols: perspectives for synthesis and H2 storage. ChemCatChem 1, 72-73 (2009).

10. Chase, M. W. NIST-JANAF Thermochemical Tables. (American Chemical Society; American Institute of Physics for the National Institute of Standards and Technology, Washington, DC: New York, 1998).

11. Nielsen, M., Junge, H., Kammer, A. \& Beller, M. Towards a green process for bulk-scale synthesis of ethyl acetate: efficient acceptorless dehydrogenation of ethanol. Angew. Chem. Int. Ed. 51, 5711-5713 (2012).

12. Requies, J. et al. Biobutanol dehydrogenation to butyraldehyde over $\mathrm{Cu}, \mathrm{Ru}$ and $\mathrm{Ru}-\mathrm{Cu}$ supported catalysts. Noble metal addition and different support effect. Catal. Lett. 142, 50-59 (2012).

13. Chatterjee, M., Ishizaka, T., Chatterjee, A. \& Kawanami, H. Dehydrogenation of 5-hydroxymethylfurfural to dyformylfuran in compressed carbon dioxide: an oxidant free approach. Green. Chem. 19, 1315-1326 (2017).

14. Wang, F. et al. Highly efficient dehydrogenation of primary aliphatic alcohols catalyzed by $\mathrm{Cu}$ nanoparticles dispersed on rod-shaped $\mathrm{La} 2 \mathrm{O} 2 \mathrm{CO} 3$. ACS Catal. 50, 9593-9597 (2011)

15. Nielsen, M. et al. Efficient hydrogen production from alcohols under mild reaction conditions. Angew. Chem. Int. Ed. 50, 9593-9597 (2011).

16. Musa, S., Shaposhnikov, I., Cohen, S. \& Gelman, D. Ligand-metal cooperation in PCP pincer complexes: rational design and catalytic activity in acceptorless dehydrogenation of alcohols. Angew. Chem. Int. Ed. 50, 3533-3537 (2011).

17. Kawahara, R., Fujita, K.-I. \& Yamaguchi, R. Cooperative catalysis by iridium complexes with a bipyridonate ligand: versatile dehydrogenative oxidation of alcohols and reversible dehydrogenation-hydrogenation between 2-propanol and Acetone. Angew. Chem. Int. Ed. 51, 12790-12794 (2012).

18. Zheng, G., Sakaki, S., Fujita, K.-I., Sano, H. \& Yamaguchi, R. Efficient catalyst for acceptorless alcohol dehydrogenation: interplay of theoretical and experimental studies. ACS Catal. 4, 1010-1020 (2014).

19. Chelucci, G., Baldino, S. \& Baratta, W. Recent advances in osmium-catalyzed hydrogenation and dehydrogenation reactions. Acc. Chem. Res. 48, 363-379 (2015).

20. Guillena, G., Ramon, D. J. \& Yus, M. Alcohols as electrophiles in C-C bondforming reactions: the hydrogen autotransfer process. Angew. Chem. Int. Ed. 46, 2358-2364 (2007).

21. Crabtree, R. H. Homogeneous transition metal catalysis of acceptorless dehydrogenative alcohol oxidation: applications in hydrogen storage and to heterocycle synthesis. Chem. Rev. 117, 9228-9246 (2017)

22. Kim, W. H., Park, I. S. \& Park, J. Acceptor-free alcohol dehydrogenation by recyclable ruthenium catalyst. Org. Lett. 8, 12 (2006).

23. Kon, K., Hakim, S. S. M. A. \& Shimizu, K. Size- and support-dependent Pt nanocluster catalysis for oxidant-free dehydrogenation of alcohols. J. Catal. 304, 63-71 (2013).

24. Nicolau, G., Tarantino, G. \& Hammond, C. Acceptorless alcohol dehydrogenation catalysed by Pd/C. ChemSusChem 12, 4953-4961 (2019).

25. Yi, J. et al. A reusable unsupported rhenium nanocrystalline catalyst for acceptorles dehydrogenation of alcohols through $\gamma-\mathrm{C}-\mathrm{H}$ activation. Angew. Chem. Int. Ed. 53, 833-836 (2014).

26. Mitsudome, T. et al. Oxidant-free alcohol dehydrogenation using a reusable hydrotalcite-supported silver nanoparticle catalyst. Angew. Chem. Int. Ed. 47, 138-141 (2008).

27. Bayat, A., Shakourian-Fard, M., Ehyaei, N. \& Hashemi, M. M. Silver nanoparticles supported on silica-coated ferrite as magnetic and reusable catalysts for oxidant-free alcohol dehydrogenation. RSC Adv. 5, 22503-22509 (2015).

28. Fang, W.-H., Chen, J.-S., Zhang, Q.-H., Deng, W.-P. \& Wang, Y. Hydrotalcitesupported gold catalyst for the oxidant-free dehydrogenation of benzyl alcohol: studies on support and gold size effects. Chem. Eur. J. 17, 1247-1256 (2011).

29. Filonenko, G. A., van Putten, R., Hensen, E. J. M. \& Pidko, E. A. Catalytic (De) hydrogenation promoted by non-precious metals - Co, Fe and Mn: recent advances in an emerging field. Chem. Soc. Rev. 47, 1459-1483 (2018).

30. Mitsudome, T. et al. Copper nanoparticles on hydrotalcite as a heterogeneous catalyst for oxidant-free dehydrogenation of alcohols. Chem. Commun. 44, 4804-4806 (2008).

31. Shimizu, K. et al. Heterogeneous cobalt catalysts for the acceptorless dehydrogenation of alcohols. Green. Chem. 15, 418-424 (2013).

32. Kazmierczak, K. et al. Importance of decoration in shaped cobalt nanoparticles in the acceptorless secondary alcohol dehydrogenation. Catal. Sci. Technol. 10, 4923-4937 (2020).

33. Shimizu, K., Kon, K., Seto, M., Shimura, K. \& Hakim Siddiki, S. M. A. Acceptor-free dehydrogenation of secondary alcohols by heterogeneous cooperative catalysis between $\mathrm{Ni}$ nanoparticles and acid-base sites of alumina supports. J. Catal. 300, 242-249 (2013)

34. Chen, H. et al. Promoted synergic catalysis between metal ni and acid-base sites toward oxidant-free dehydrogenation of alcohols. ACS Catal. 7, 2735-2743 (2017).
35. Hakim Siddiki, S. M. A., Toyao, T. \& Shimizu, K.-I. Acceptorless dehydrogenative coupling reactions with alcohols over heterogeneous catalysts. Green. Chem. 20, 2933-2952 (2018).

36. van Santen, R. A. \& Neurock, M. Molecular Heterogeneous Catalysis: A Conceptual and Computational Approach. (Wiley-VCH, Weinheim, 2006).

37. Nøskov, J. K., Studt, F., Abild-Pedersen, F. \& Bligaard, T. Fundamental Concepts in Heterogeneous Catalysis. (John Wiley \& Sons, Inc, Hoboken, New Jersey, 2014).

38. Greeley, J. \& Mavrikakis, M. A first-principles study of methanol decomposition on Pt(111). J. Am. Chem. Soc. 124, 7193-7201 (2002).

39. Desai, S. K., Neurock, N. \& Kourtakis, K. A periodic density functional theory study of the dehydrogenation of methanol over Pt(111). J. Phys. Chem. B 106 2559-2568 (2002).

40. Jiang, R. B., Guo, W. Y., Li, M., Fu, D. L. \& Shan, H. H. Density functional investigation of methanol dehydrogenation on $\mathrm{Pd}(111)$. J. Phys. Chem. C 113, 4188-4197 (2009).

41. Wang, H., He, C. Z., Huai, L. Y. \& Liu, J. Y. Decomposition and oxidation of methanol on $\operatorname{Ir}(111)$ : A first-principles study. J. Phys. Chem. C 117, 4574-4584 (2013).

42. Michel, C., Auneau, F., Delbecq, F. \& Sautet, P. C-H versus O-H bond dissociation for alcohols on a $\mathrm{Rh}(111)$ surface: a strong assistance from hydrogen bonded neighbors. ACS Catal. 1, 1430-1440 (2011).

43. Wang, G. C. et al. Kinetic Mechanism of Methanol Decomposition on $\mathrm{Ni}(111)$ Surface: a Theoretical Study. J. Phys. Chem. B 109, 12431-12442 (2005).

44. Greeley, J. \& Mavrikakis, M. Methanol decomposition on $\mathrm{Cu}(111)$ : a DFT study. J. Catal. 208, 291-300 (2002)

45. Garcia-Muelas, R., Li, Q. \& Lopez, N. Density functional theory comparison of methanol decomposition and reverse reactions on metal surfaces. ACS Catal. 5, 1027-1036 (2015).

46. Zaffran, J., Michel, C., Delbecq, F. \& Sautet, P. Trade-off between accuracy and universality in linear energy relations for alcohol dehydrogenation on transition metals. J. Phys. Chem. C. 119, 12988-12998 (2015).

47. Liu, B. \& Greeley, J. A density functional theory analysis of trends in glycerol decomposition on close-packed transition metal surfaces. Phys. Chem. Chem. Phys. 15, 6475-6485 (2013).

48. Lausche, A. C., Hummelshøj, J. S., Abild-Pedersen, F., Studt, F. \& Nørskov, J. K. Application of a new informatics tool in heterogeneous catalysis: analysis of methanol dehydrogenation on transition metal catalysts for the production of anhydrous formaldehyde. J. Catal. 291, 133-137 (2012).

49. Khan, T. S., Jalid, F. \& Haider, M. A. First-principle microkinetic modeling of ethanol dehydrogenation on metal catalyst surfaces in non-oxidative environment: design of bimetallic alloys. Top. Catal. 61, 1820-1831 (2018).

50. Medford, A. J. et al. CatMAP: a software package for descriptor-based microkinetic mapping of catalytic trends. Catal. Lett. 145, 794-807 (2015).

51. Abild-Pedersen, F. et al. Scaling properties of adsorption energies for hydrogen-containing molecules on transition-metal surfaces. Phys. Rev. Lett. 99, 016105 (2007)

52. van Santen, R. A., Neurock, M. \& Shetty, S. G. Reactivity theory of transition metal surfaces: a brønsted-Evans-polanyi linear activation energy-freeenergy analysis. Chem. Rev. 110, 2005-2048 (2010).

53. Burcat, A. \& Ruscic, B. Third Millennium Ideal Gas and Condensed Phase Thermochemical Database for Combustion with Updates from Active Thermochemical Tables, ANL-05/20 and TAE \# 960 report, Technion-IIT Aerospace Engineering and Argonne National Laboratory Chemistry Division, (2005).

54. Wang, T. et al. Rational design of selective metal catalysts for alcohol amination with ammonia. Nat. Catal. 2, 773-779 (2019).

55. Hannagan, R. T., Giannakakis, G., Flytzani-Stephanopoulos, M. \& Sykes, E. C. H. Single-atom alloy catalysis. Chem. Rev. 120, 12044-12088 (2020).

56. Oyama, S. T. Preparation and catalytic properties of transition metal carbides and nitrides. Catal. Today 15, 179-200 (1992).

57. Wang, T. et al. Stability of $\beta-\mathrm{Mo} 2 \mathrm{C}$ facets from ab initio atomistic thermodynamics. J. Phys. Chem. C. 115, 22360-22368 (2011).

58. Kresse, G. \& Furthmüller, J. Efficient iterative schemes for ab initio totalenergy calculations using a plane-wave basis set. Phys. Rev. B 54, 11169-11186 (1996).

59. Blochl, P. E. Projector Augmented-Wave Method. Phys. Rev. B 50, 17953-17979 (1994)

60. Perdew, J. P., Burke, K. \& Ernzerhof, M. Generalized gradient approximation made simple. Phys. Rev. Lett. 77, 3865-3868 (1996).

61. Methfessel, M. \& Paxton, A. T. High-precision Sampling for Brillouin-zone Integration in Metals. Phys. Rev. B 40, 3616-3621 (1989).

62. Steinmann, S. N. \& Corminboeuf, C. Comprehensive benchmarking of a density-dependent dispersion correction. J. Chem. Theory Comput. 7, 3567-3577 (2011)

63. Henkelman, G. \& Jónsson, H. A climbing image nudged elastic band method for finding saddle points and minimum energy paths. J. Chem. Phys. 113 9978-9985 (2000). 


\section{Acknowledgements}

T.W. acknowledges the start-up fund of Westlake University and Westlake University HPC Center for computation support. T.W. also thanks Professor Licheng Sun for the insightful discussions and helpful suggestions as well as financial support to this project. The authors thank the SYSPROD project and AXELERA Pôle de Compétitivité for financial support (PSMN Data Center). C.M., M.P.T., and P.S. acknowledge the financial support by the ANR grant SHAPES (13-CDII-0004-06).

\section{Author contributions}

P.S., M.P.T., C. M., M.S., and T.W. conceived the ideas behind this study; T.W. performed all the computations, micro-kinetics simulations, and data analysis; J.S. did the experiments; all the authors contributed to writing and editing the paper.

\section{Competing interests}

The authors declare no competing interests.

\section{Additional information}

Supplementary information The online version contains supplementary material available at https://doi.org/10.1038/s41467-021-25214-1.

Correspondence and requests for materials should be addressed to T.W., P.S., M.P.-T. or C.M.
Peer review information Nature Communications thanks the anonymous reviewer(s) for their contribution to the peer review of this work.

Reprints and permission information is available at http://www.nature.com/reprints

Publisher's note Springer Nature remains neutral with regard to jurisdictional claims in published maps and institutional affiliations.
Open Access This article is licensed under a Creative Commons Attribution 4.0 International License, which permits use, sharing, adaptation, distribution and reproduction in any medium or format, as long as you give appropriate credit to the original author(s) and the source, provide a link to the Creative Commons license, and indicate if changes were made. The images or other third party material in this article are included in the article's Creative Commons license, unless indicated otherwise in a credit line to the material. If material is not included in the article's Creative Commons license and your intended use is not permitted by statutory regulation or exceeds the permitted use, you will need to obtain permission directly from the copyright holder. To view a copy of this license, visit http://creativecommons.org/ licenses/by/4.0/

(C) The Author(s) 2021 